\title{
Optimal Strategies for Low Carbon Supply Chain with Strategic Customer Behavior and Green Technology Investment
}

\author{
Wen Jiang ${ }^{1}$ and Xu Chen ${ }^{2}$ \\ ${ }^{1}$ College of Architecture and Urban-Rural Planning, Sichuan Agricultural University, Chengdu 611830, China \\ ${ }^{2}$ School of Management and Economics, University of Electronic Science and Technology of China, Chengdu 611731, China \\ Correspondence should be addressed to Xu Chen; xchenxchen@263.net
}

Received 5 November 2015; Accepted 13 January 2016

Academic Editor: Jorge J. Júlvez

Copyright (c) 2016 W. Jiang and X. Chen. This is an open access article distributed under the Creative Commons Attribution License, which permits unrestricted use, distribution, and reproduction in any medium, provided the original work is properly cited.

\begin{abstract}
Climate change is mainly caused by excessive emissions of carbon dioxide and other greenhouse gases. In order to reduce carbon emissions, cap and trade policy is implemented by governments in many countries, which has significant impacts on the decisions of companies at all levels of the low carbon supply chain. This paper investigates the decision-making and coordination of a low carbon supply chain consisting of a low carbon manufacturer who produces one product and is allowed to invest in green technology to reduce carbon emissions in production and a retailer who faces stochastic demands formed by homogeneous strategic customers. We investigate the optimal production, pricing, carbon trading, and green technology investment strategies of the low carbon supply chain in centralized (including Rational Expected Equilibrium scenario and quantity commitment scenario) and decentralized settings. It is demonstrated that quantity commitment strategy can improve the profit of the low carbon supply chain with strategic customer behavior. We also show that the performance of decentralized supply chain is lower than that of quantity commitment scenario. We prove that the low carbon supply chain cannot be coordinated by revenue sharing contract but by revenue sharing-cost sharing contract.
\end{abstract}

\section{Introduction}

In recent years, global warming resulting from excess emissions of carbon dioxide and other greenhouse gases has been challenging the survival and development of human beings, leading to serious consequences like droughts, heat waves, sea level rise, intense rainfall, and so forth. Research shows that global warming is mainly caused by human activities (at least 90\% probability) [1]. Therefore, achieving a sustainable low carbon economy by changing the mode of human production and life has become the focus of global attention [2]. Developing low carbon economy also challenges the supply chain management. In addition to the development of carbon reduction technology and new energy technologies, increasing number of researchers and entrepreneurs pay attention to the optimization of supply chain operation strategy to reduce carbon emissions.

In order to meet the goal of carbon emissions reduction, the governments all over the world tend to implement carbon emission regulation policies. Compared with other regulation policies, cap and trade policy is effective in reducing corporate carbon emissions without increasing costs significantly [3] and has obvious advantages in feasibility, fairness, and business participation [4]. Cap and trade policy has become the preference of governments as it achieves the goal of effective carbon reduction through dual means of regulation and market [5].

The implementation of cap and trade policy makes the carbon emission permits the essential factors of production. For supply chain businesses, in addition to carbon emissions trading, investing in production process improvement, carbon capture, and storage technologies of production process is another way to get carbon emission permits $[6,7]$. Green technology investment will increase production cost but also can save carbon emissions for businesses and get additional revenue. Furthermore, customers tend to buy low carbon products with the gradual increase of the environmental awareness among them [8]. By investing in green technology, 
customers can meet the low carbon demand of customers and obtain the corresponding competitive advantage. Businesses in supply chain needs to trade off the costs and benefits of green technology investment to decide whether to invest. Therefore, under the cap and trade policy, study on low carbon supply chain operation strategies optimization with green technology investment is of great theoretical value.

In recent years, scholars and practitioners have taken greater interests in strategic customer behavior, which is shown in the increasing marketing and operations research literature on the problem. Strategic customer behavior refers to the behavior of customers who do not buy products at full price but wait until the products markdown. Research shows that the ignorance of the strategic customer behavior in operation strategies would be harmful to the performance of supply chain $[9,10]$. Strategic customer behavior has become a common phenomenon in perishable product sales process, which made it a regular assumption in many literatures [1113]. Therefore, considering strategic customer behavior, to study low carbon supply chain strategies and coordination is more realistic.

The production, pricing, carbon trading, and green technology investment problems are examined in a supply chain setting made up of a retailer and a manufacturer. The manufacturer can invest in green technology to reduce unit carbon emissions of the product and distribute the product to strategic customers through the retailer. Three key questions are addressed in the paper.

(1) In centralized supply chain setting, what is the optimal production quantity, pricing, carbon trading strategy, and green technology investment?

(2) In centralized supply chain setting, can quantity commitment improve the supply chain performance and what effect does the quantity commitment have on the supply chain strategies?

(3) In decentralized supply chain setting, what is the optimal strategies for the retailer and manufacturer, respectively? How to coordinate the decentralized supply chain to achieve the performance in quantity commitment scenario?

After a review of the literature in Section 2, we present the model descriptions and assumptions in Section 3. In Section 4, the centralized supply chain setting models are discussed. We obtain the optimal strategies for the centralized decision-maker in scenarios of Rational Expectations Equilibrium (RE Equilibrium) and quantity commitment (QC), respectively. In Section 5, the optimal strategies for the manufacturer and the retailer in decentralized supply chain setting are discussed. We design supply chain coordination mechanism in Section 6. In Section 7, we present conclusions of our findings and highlight possible future work.

\section{Literature Review}

There are two streams of literature closely related to our work: literature on low carbon supply chain management and literature on supply chain business decisions with strategic customer behavior.

The literature on low carbon supply chain management can be further divided into two classes. One is the research on centralized supply chain, that is, single business decisions, and the other is the research on decentralized supply chain decisions and coordination. As to the literature on single business decisions, a lot of researchers examined the impact of cap and trade policy without green technology investment, such as Dobos, 2005 [14], Chen et al., 2015 [15], Chen and Wang, 2015 [16], and Chang et al., 2015 [17]. This stream of literature explores the research framework that examines the effect of cap and trade policy on low carbon supply chain decisions but the green technology investment is not included. Meanwhile, a lot of researchers have introduced green technology investment into low carbon supply chain management. Zhao et al., 2010 [18], developed a carbon emissions allowance allocation system with green technology investment in electric power market. Yalabik and Fairchild, 2011 [19], investigated the manufacturer's investment decision on environmentally friendly product with customer behavior and government regulation. They showed that the manufacturer had an incentive to carry out green technology investments to reduce carbon emissions when the customer demand was emissions-sensitive. Toptal et al., 2014 [20], investigated the joint decisions of procurement and green technology investment under carbon tax and cap and trade policy, respectively. They also discussed the effect of different carbon policies on the decision of green technology investment. In Manikas and Kroes, 2015 [21], a forward buying heuristic is designed for those firms who get carbon emissions by auctions. As to the literature on decentralized supply chain decisions and coordination without green technology investment, Benjaafar et al., 2013 [22], introduced carbon emissions into the simple supply chain system and investigated the procurement, production, inventory, and green technology investment decisions with cap and trade policy. $\mathrm{Xu}$ et al., 2015 [23], studied the production and pricing problem of a MTO supply chain consisting of a two-product manufacturer and a retailer. The manufacturer is constrained by cap and trade policy and determines the wholesale price of the two products. Zhen et al., 2015 [24], examined the retailer's optimal pricing, ordering, and transportation mode strategies with cap and trade policy. They showed that the retailer preferred low carbon transportation mode with cap and trade policy under certain conditions. There are a few literatures on decentralized supply chain decisions and coordination with green technology investment. Swami and Shah, 2013 [25], considered the customer's environmental awareness, that is, the green technology investments of firms in the supply chain would affect the customer demand, and design a coordination mechanism for the supply chain based on costs sharing contract.

As to the literature on supply chain business decisions with strategic customer behavior, Coase, 1972 [26], first paid attention to strategic customer behavior in economics. He found that when the monopoly company faced strategic customer, the monopoly company would set the margin cost as the price and earn zero profit. We review 
this stream literature from two aspects of centralized and decentralized supply chain decisions with strategic customer behavior. $\mathrm{Su}, 2007$ [27], investigated the dynamic pricing of a monopolist selling a finite inventory over a finite time period. The demand was endogenous and intertemporal. The customers were heterogeneous and strategic. The research shows that the heterogeneous valuation and patience of customers determine the optimal pricing policies structure. Zhang and Cooper, 2008 [28], considered a firm that sells a single product over two periods and examined the effects of strategic customer behavior on the firm's rationing and pricing decisions. Their research shows that when prices were fixed in advance, rationing could improve revenue. Whang, 2015 [29], considered heterogeneous strategic customers with different reservation value and studied the effect of demand uncertainly on the retailer's markdown policy. Du et al., 2015 [30], taking strategic customers into consideration with risk preference and decreasing value, studied the joint stock and pricing decision problem. Compared with classical newsboy models, the ordering quantity and total profit got lower when strategic customer behavior was taken into consideration. As to the effects of strategic customer behavior on the decentralized supply chain performance and coordination strategy, Su and Zhang, 2008 [31], examined the effect of strategic customer behavior on the performance of supply chain and the valve of commitment. They characterized Rational Expected Equilibrium between strategic customers and the retailer. They showed that quantity commitment could improve the seller's profit and decentralization could improve the supply chain performance. Yang, 2012 [32], studied the effect of competition and discounting on the performance of decentralized supply chain with strategic customer behavior. It showed that the performance of a centralized supply chain was lower than that of a decentralized supply chain when strategic customers existed. It showed that retailer competition and the firm and customer discounting were also driving factors of higher decentralized supply chain performance except for double marginalization effect. Yang et al., 2015 [33], addressed the effect of quick response on the performance of supply chain when strategic customer behavior was taken into consideration. They compared the quick response value in different supply chain structures. They showed that a decentralized supply chain with revenue sharing contracts could achieve the performance of a centralized supply chain, but allocating the profit arbitrary in supply chain members could not be realized here.

Nevertheless, despite the increased attention on low carbon supply chain management in operations management literature, very few studies have been carried by considering green technology investments and cap and trade policy simultaneously. To the best of our knowledge, there are no published works that introduce strategic customer behavior into low carbon supply chain framework to investigate the optimal production, pricing, carbon trading, and green technology investment decisions. One distinction of our model is examining the optimal strategies of low carbon supply chain by considering cap and trade policy, green technology investment, and strategic customer behavior simultaneously. Another distinction is systematic consideration of optimizing low carbon strategies in centralized and decentralized scenarios. The contributions of our work are as follows: first, we obtain the optimal production, pricing, carbon trading, and green technology investment strategies for companies at all levels of low carbon supply chain in different scenarios. Second, we analyze the impact of quantity commitment on the operation strategies of a centralized supply chain and its performance. Third, coordination mechanisms for low carbon supply chain with strategic customer behavior are designed based on revenue sharing-cost sharing contract.

\section{Model Descriptions and Assumptions}

We examine a two-echelon low carbon supply chain made up of a low carbon manufacturer and a retailer. The manufacturer produces a product and distributes it to customers through the retailer. We divide the wholesales period of the retailer into two phases. The retailer sells the product at full price in phase one and at salvage price in phase two. If the product is sold out in phase one, phase two does not exist. The customers are homogeneous strategic customers who will take into account the possibility of buying the product at salvage price to choose buying the product at full price or wait to purchase the product at salvage price to maximize the expected surplus. Each customer purchases one product at most.

Variables and parameters for model development adopted in this study are denoted as in Notations section.

Because the parameters must meet certain conditions to make sense, we assume the following:

(1) $p \leq r$. Only when the retail price is no more than the customer reservation price, the customer may purchase the product at full price.

(2) $v>p>w>c>s>0$. This condition ensures that there is a positive profit margin for the manufacturer, retailer, and customers when a product is sold to customers. In addition, the production cost is greater than the salvage price, which indicates that the retailer will lose money when the product fails to sell at full price. This prompts the retailer to order the products according to the customers' demand, because the excess inventories generate losses.

(3) $w>c+k$. This condition states that the manufacturer is willing to produce products with cap and trade policy. Otherwise the manufacturer will not produce products but sell carbon emissions to earn profits.

(4) The shortage cost of the manufacturer and operating cost of the retailer are not taken into consideration.

(5) We assume that the manufacturer and the retailer are all rational and self-interested; that is, both of them aim to maximize their profit. We also assume that they are risk neutral.

(6) The carbon emissions in production is the main source of the total carbon emissions. So we only consider the carbon emissions of production. 
(7) The green technology investment is the function of $\tau$, denoted by $I(\eta)$. We assume that $I(\eta) \geq 0$, $I^{\prime}(\eta)>0$, and $I^{\prime \prime}(\eta)>0$. This is consistent with the practice. The conditions show that the margin green technology investment is increasing in carbon emissions reduction rate. Referring to d'Aspremont and Jacquemin, 1988 [34], we set $I(\eta)=(1 / 2) t \eta^{2}$, where $t$ represents the efficiency of green technology investments.

Variables and parameters related to low carbon include $e$ (a decision variable which represents the carbon emissions trading policy), $\eta$ (a decision variable which represents the green technology investment policy), and $E$ and $k$ (represent the initial carbon emissions and unit price of carbon emissions trading, resp.).

\section{Centralized Supply Chain Model}

In this section, we assume that the manufacturer is authorized to determine the production, pricing, carbon trading, and green technology investment strategies under cap and trade policy to maximize the profit of the centralized supply chain. At the beginning, the government allocates a certain amount of free carbon emissions to the manufacturer. During the producing process, if the carbon emission is limited, the manufacturer should buy extra carbon emissions from the external market. Otherwise, if the carbon emission is enough, the manufacturer could sell extra carbon emissions to gain revenue. At the end of the period, carbon emissions of the manufacturer must not exceed the carbon emission rights it holds.

The sequence of events in this part is as follows: first, the manufacturer forms the belief of customers' reservation price $\xi_{r}$ and then decides the retail selling price, product quantity, carbon trading volume, and green technology investment; second, the customers form the beliefs $\xi_{\text {prob }}$ of probability of the product sold at salvage price $s$ according to the information of market price and then form the reservation price $r$; third, the customers' demand is satisfied and the products are sold at full price $p$; finally, all remaining products are sold to the external market at salvage price $s$.

4.1. Rational Expectations Equilibrium Scenario. We characterize the RE Equilibrium between the manufacturer and the strategic customers. Muth, 1961 [35], first proposed rational expectations hypothesis, which refers to the situation that there is no systematic bias between the actual economic result and people's expectations. Then, Su and Zhang, 2008 [31], introduced it into operations management to analyze the decision problems of the enterprises when strategic customer behavior is taken into account. Since then, the rational expectations hypothesis has been adopted by scholars all over the world $[13,27,30]$.

First, we examine the decision problem of strategic customers. The customers choose to buy the product immediately at price $p$ or wait for markdown to maximize their expected surplus. The customer surplus is $v-p$ when the customer buys the product at full price and $(v-s) \xi_{\text {prob }}$ at salvage price. Therefore, the maximum expected surplus of the customer is $\max \left\{(v-s) \xi_{\text {prob }}, v-p\right\}$. If and only if $(v-$ $s) \xi_{\text {prob }} \leq v-p$, the customer will buy the product at full price. So given $\xi_{\text {prob }}$, we can obtain the customer's reservation price $r\left(\xi_{\text {prob }}\right)=v-(v-s) \xi_{\text {prob }}$.

Then, we examine the decision problem of the manufacturer. The profit function of the manufacturer with cap and trade policy and green technology investment, denoted by $\pi(q, p, e, \eta)$, is

$$
\begin{aligned}
\pi(q, p, e, \eta)= & (p-s)\left(q-\int_{0}^{q} F(x) d x\right)-(c-s) q \\
& -k e-\frac{1}{2} t \eta^{2} .
\end{aligned}
$$

First two items represent the manufacturer's expected profit without cap and trade policy and green technology investment. This is the same with the newsvendor model. The third item represents the carbon emissions trading cost/profit of the manufacturer. The forth item represents the cost of manufacturer investing in green technology.

The carbon trading volume after green technology investment under cap and trade policy is

$$
e=(1-\eta) q-E
$$

First term represents the manufacturer's carbon emissions in production after green technology investment; the second term represents initial free carbon emission owned by the manufacturer.

Then $\pi(q, p, e, \eta)$ can be transformed into

$$
\begin{aligned}
\pi(q, p, \eta)= & (p-s)\left(q-\int_{0}^{q} F(x) d x\right) \\
& -(c-s+k(1-\eta)) q+k E-\frac{1}{2} t \eta^{2} .
\end{aligned}
$$

The beliefs of the manufacturer over the customer's reservation price are $\xi_{r}$. Obviously, the manufacturer will set $p=\xi_{r} ; q$ and $\eta$ are the maximizer $\max _{q, \eta} \pi(q, p, \eta)$ when given $p$. According to the definition of RE Equilibrium, the RE Equilibrium solution $\left(p, q, \eta, r, \xi_{r}, \xi_{\text {prob }}\right)$ must meet

$$
\begin{gathered}
r=v-(v-s) \xi_{\text {prob }}, \\
p=\xi_{r}, \\
(q, \eta)=\arg \max _{q, \eta} \pi(q, p, \eta), \\
\xi_{\text {prob }}=F(q), \\
\xi_{r}=r .
\end{gathered}
$$

Conditions (4), (5), and (6) indicate that the manufacturer and customers will choose the action to maximize their own utility. Conditions (7) and (8) can ensure that the solution meets rational expectations hypothesis, that is, the actual situation of economic operation in line with people's expectations. 
The Rational Expectations Equilibrium makes

$$
p=v-(v-s) F(q) \text {. }
$$

The production, pricing, and green technology investment decision model of the manufacturer with cap and trade policy and green technology investment is

$$
\begin{array}{ll}
\max _{q, \eta} & \pi(q, p, \eta), \\
\text { s.t. } & (1-\eta) q \leq E .
\end{array}
$$

Defining $\theta_{1}(q)=(1 /(1-\eta))[(p-s) \bar{F}(q)-(c-s)]$, $\theta_{2}(\eta)=t \eta / q . \theta_{1}(q)$ represents the margin profit of unit carbon emission, that is, the profit gained by the manufacturer with one unit carbon emission input in production; $\theta_{2}(\eta)$ represents the margin cost of unit carbon emission, that is, the cost that the manufacturer invests in green technology to get one unit carbon emission reduction.

Lemma 1. Given $p$ and $(v-s) f(q) \bar{F}(q) t-k^{2}>0, \pi(q, p, \eta)$ is a joint concave function of $\eta$ and $q$ in RE Equilibrium.

Proof. Given $p$, according to formula (3), $\partial \pi(q, p, \eta) / \partial q=$ $(p-s) \bar{F}(q)-(c-s)-(1-\eta) k, \partial^{2} \pi(q, p, \eta) / \partial q^{2}=-(p-s) f(q)<$ $0 \partial \pi(q, p, \eta) / \partial \eta=q k-t \eta, \partial^{2} \pi(q, p, \eta) / \partial \eta^{2}=-t<0$, and $\partial^{2} \pi(q, p, \eta) / \partial q \partial \eta=\partial^{2} \pi(q, p, \eta) / \partial \eta \partial q=k$.

When $t(v-s) f(q) \bar{F}(q)-k^{2}>0$, under RE Equilibrium, we get $t(p-s) f(q)-k^{2}>0$; then we have $\partial^{2} \pi(q, p, \eta) / \partial q \partial \eta=$ $\partial^{2} \pi(q, p, \eta) / \partial \eta \partial q=k$ and

$$
\begin{aligned}
& \left|\begin{array}{ll}
\frac{\partial^{2} \pi(q, p, \eta)}{\partial q^{2}} & \frac{\partial^{2} \pi(q, p, \eta)}{\partial q \partial \eta} \\
\frac{\partial^{2} \pi(q, p, \eta)}{\partial \eta \partial q} & \frac{\partial^{2} \pi(q, p, \eta)}{\partial \eta^{2}}
\end{array}\right|=t(p-s) f(q)-k^{2} \\
& >0
\end{aligned}
$$

The Hessian Matrix of the problem is negative definite, and then we can prove that $\pi(q, p, \eta)$ is joint concave function of $q$ and $\eta$ when given $p$ and $(v-s) f(q) \bar{F}(q) t-k^{2}>0$. This completes the proof.

As to the manufacturer's optimal production quantity (denoted by $q^{*}$ ), pricing (denoted by $p^{*}$ ), carbon trading $\left(\right.$ denoted by $e^{*}$ ), and green technology investment (denoted by $\left.\eta^{*}\right)$, the following proposition is obtained.

Proposition 2. If $(v-s) f(q) \bar{F}(q) t-k^{2}>0$, the manufacturer's optimal production quantity $\left(q^{*}\right)$, pricing $\left(p^{*}\right)$, carbon trading $\left(e^{*}\right)$, and green technology investment $\left(\eta^{*}\right)$ strategies satisfy

$$
\begin{aligned}
\theta_{1}\left(q^{*}\right) & =\theta_{2}\left(\eta^{*}\right)=k, \\
p^{*} & =s+(v-s) \bar{F}\left(q^{*}\right), \\
e^{*} & =\left(1-\eta^{*}\right) q^{*}-E,
\end{aligned}
$$

Proof. According to Lemma 1, if $(v-s) f(q) \bar{F}(q) t-k^{2}>0$, let $\partial \pi(q, p, \eta) / \partial q=0, \partial \pi(q, p, \eta) / \partial \eta=0$ and combine (9) and (2); we get

$$
\begin{aligned}
&(p-s) \bar{F}(q)-(c-s)-(1-\eta) k=0, \\
& q k-t \eta=0, \\
& p=v-(v-s) \bar{F}(q), \\
& e=(1-\eta) q-E, \\
& 0<\eta<1 .
\end{aligned}
$$

Solving the equations above can derive the optimal production, pricing, carbon trading, and green technology investment strategies of the manufacturer. This completes the proof.

Proposition 2 shows that, considering strategic customer behavior, the manufacturer's optimal production quantity, pricing, carbon trading volume, and green technology investment strategy with cap and trade policy and green technology investment exist and are unique. The inherent implication of the proposition is very intuitive. $\theta_{1}(q)$ represents the margin profit of unit carbon emission, $\theta_{2}(\eta)$ represents the margin cost of unit carbon emission, and $k$ is the unit carbon emission trading price which can be seen as marginal cost or profit by carbon emission trading. The optimal strategies of the manufacturer are that the margin profit of unit carbon emission is equal to the margin cost of unit carbon emission. The marginal cost of getting unit carbon emission from different way (green technology investment or buying) is equal. The marginal profit of unit carbon emission for different uses (production or sale) is equal.

Substitute $q^{*}, p^{*}$, and $\eta^{*}$ into (3); we can obtain the maximum expected profit of the manufacturer with cap and trade policy and green technology investment: $\pi\left(q^{*}, p^{*}, \eta^{*}\right)=$ $\left(p^{*}-s\right)\left(q^{*}-\int_{0}^{q^{*}} F(x) d x\right)-\left(c-s+k\left(1-\eta^{*}\right)\right) q^{*}+k E-(1 / 2) t \eta^{* 2}$.

4.2. Quantity Commitment Scenario. In traditional literature on strategic customer behavior, quantity commitment can improve the manufacturer's expected profit. Quantity commitment refers to the action in which the manufacturer promises customers that only a certain number of products is produced and sold. In low carbon supply chain setting, can the maximum expected profit be improved by quantity commitment? We attempt to answer the question in this paper.

We assume that the manufacturer can convince customers by appropriate means that they only can obtain $q$ units of the product in the wholesales period. At this time, the strategic customers no longer need to anticipate the probability of getting the product at salvage price. When $q$ is given, the probability of being able to get the product at price $s$ is $F(q)$. The reservation price is $p(q)=v-(v-s) F(q)$, which also is the optimal pricing of the manufacturer. We have $e=(1-\eta) q-E$; then we can obtain the expected profit 
function of the manufacturer with respect to $q$ and $\eta$, denoted by $\pi^{q}(q, \eta)$ :

$$
\begin{aligned}
\pi^{q}(q, \eta)= & (v-s) \bar{F}(q)\left(q-\int_{0}^{q} F(x) d x\right) \\
& -(c-s+k(1-\eta)) q+k E-\frac{1}{2} t \eta^{2} .
\end{aligned}
$$

So, the manufacturer's optimal production quantity and carbon reduction rate in QC scenario are $\left(q^{q *}, \eta^{q^{*}}\right)=$ $\arg \max _{q \geq 0,0<\eta<1} \pi^{q}(q, \eta)$, the optimal price is $p^{q *}=v-(v-$ s) $F\left(q^{q *}\right)$, and the optimal carbon trading volume is $e^{q *}=$ $\left(1-\eta^{q *}\right) q^{q^{*}}-E$.

Lemma 3. Given q, the optimal green technology investment strategy of the manufacturer, denoted by $\eta^{q *}$, satisfies

$$
\eta^{q *} \equiv \eta(q)=\frac{k q}{t}, \quad 0<\eta^{q *}<1 .
$$

Proof. We have $\partial \pi^{q}(q, \eta) / \partial \eta=q k-t \eta, \partial^{2} \pi^{q}(q, \eta) / \partial \eta^{2}=-t<$ 0 . Let $\partial \pi^{q}(q, \eta) / \partial \eta=0$; we get $\eta^{q *} \equiv \eta(q)=k q / t$. In addition, according to the assumption in Section 3, we know $0<\eta^{q^{*}}<$ 1. This completes the proof.

Substituting $\eta^{q^{*}}=\eta(q)$ into (14),

$$
\begin{aligned}
\pi^{q}(q) \equiv & \pi^{q}(q, \eta(q)) \\
= & (v-s) \bar{F}(q)\left(q-\int_{0}^{q} F(x) d x\right) \\
& -(c-s+k) q+k E+\frac{k^{2} q^{2}}{2 t} .
\end{aligned}
$$

Then the two-variable optimization problem is simplified as a single variable optimization problem:

$$
\max _{q \geq 0} \pi^{q}(q) .
$$

Lemma 4. If $k^{2} / t-(v-s)\left[3 f(q) \bar{F}(q)+f^{\prime}(q)\left(q-\int_{0}^{q} F(x) d x\right)\right]<$ $0, \pi^{q}(q)$ is a concave function of $q$.

Proof. The first-order and second-order derivatives of $\pi^{q}(q)$ are

$$
\begin{aligned}
& \frac{d \pi^{q}(q)}{d q}=(v-s)\left[\bar{F}^{2}(q)-f(q)\left(q-\int_{0}^{q} F(x) d x\right)\right] \\
& -(c-s+k)+\frac{k^{2}}{t} q, \\
& \frac{d^{2} \pi^{q}(q)}{d q^{2}}=\frac{k^{2}}{t}-(v-s) \\
& \cdot\left[3 f(q) \bar{F}(q)+f^{\prime}(q)\left(q-\int_{0}^{q} F(x) d x\right)\right]<0 .
\end{aligned}
$$

Then we can obtain that $\pi^{q}(q)$ is a concave function of $q$. This completes the proof.
As to the manufacturer's optimal production quantity in QC scenario (denoted by $q^{q *}$ ), the following proposition is obtained.

Proposition 5. If $k^{2} / t-(v-s)\left[3 f(q) \bar{F}(q)+f^{\prime}(q)(q-\right.$ $\left.\left.\int_{0}^{q} F(x) d x\right)\right]<0$, the optimal production quantity in $Q C$ scenario $\left(q^{q *}\right)$ satisfies

$$
\begin{gathered}
(v-s)\left[\bar{F}^{2}(q)-f(q)\left(q-\int_{0}^{q} F(x) d x\right)\right] \\
-(c-s+k)+\frac{k^{2}}{t} q=0 .
\end{gathered}
$$

Proof. It can be directly derived according to Lemma 4 . This completes the proof.

Proposition 5 shows that, under certain condition, the optimal production quantity of the manufacturer with cap and trade and green technology investment exist and are unique.

4.3. The Effect of Quantity Commitment. The effect of QC on the optimal strategies and the maximum expected profit of the manufacturer is analyzed by comparing the optimal strategies and the maximum expected profit of the manufacturer in RE Equilibrium scenario and QC scenario.

Proposition 6. Consider $q^{q^{*}}<q^{*}, p^{q^{*}}>p^{*}, \eta^{q^{*}}<\eta^{*}$.

Proof. In order to ensure that the manufacturer's optimal strategies in the two scenarios exist, the condition $k^{2} / t<$ $\min \left\{(v-s) f(q) \bar{F}(q),(v-s)\left[3 f(q) \bar{F}(q)+f^{\prime}(q)\left(q-\int_{0}^{q} F(x) d x\right)\right]\right\}$ must be held. Then $\pi^{q}(q)$ is a concave function of $q$.

According to Proposition 2, we have $\theta_{1}\left(q^{*}\right)=\theta_{2}\left(\eta^{*}\right)=k$. $\theta_{2}\left(\eta^{*}\right)=k$ can be written as $\eta^{*}=k q^{*} / t$. Then we also can rearrange $\theta_{1}\left(q^{*}\right)=k$ to $(v-s) \bar{F}^{2}\left(q^{*}\right)-(c-s+k)+\left(k^{2} / t\right) q^{*}=0$.

We can obtain $\left.\left(d \pi^{q}(q) / d q\right)\right|_{q=q^{*}}=(v-s)\left[\bar{F}^{2}\left(q^{*}\right)-\right.$ $\left.f\left(q^{*}\right)\left(q^{*}-\int_{0}^{q^{*}} F(x) d x\right)\right]-(c-s+k)+\left(k^{2} / t\right) q^{*}=-(v-$ s) $f\left(q^{*}\right)\left(q^{*}-\int_{0}^{q^{*}} F(x) d x\right)<0$. Then we get $q^{q *}<q^{*}$. Because $\eta=k q / t$ and $p=v-(v-s) F(q)$ are held in the two scenarios, we can obtain $p^{q^{*}}>p^{*}$ and $\eta^{q^{*}}<\eta^{*}$ according to $q^{q^{*}}<q^{*}$. This completes the proof.

Proposition 6 shows that, compared with RE Equilibrium scenario, the manufacturer's optimal production quantity is lower, the optimal pricing is higher, and the optimal carbon reduction rate is lower in QC scenario.

Proposition 7. Consider $\pi^{q}\left(q^{q^{*}}, \eta^{q^{*}}\right)>\pi\left(q^{*}, p^{*}, \eta^{*}\right)$.

Proof. In order to ensure that the manufacturer's optimal strategies in the two scenarios exist, the condition $k^{2} / t<$ $\min \left\{(v-s) f(q) \bar{F}(q),(v-s)\left[3 f(q) \bar{F}(q)+f^{\prime}(q)\left(q-\int_{0}^{q} F(x) d x\right)\right]\right\}$ must be held. Then $\pi^{q}(q)$ is a concave function of $q$.

Substitute $q^{*}, p^{*}$, and $\eta^{*}=k q^{*} / t$ into (3); we have $\pi\left(q^{*}, p^{*}, \eta^{*}\right)=\pi^{q}\left(q^{*}\right)$. We know that $\pi^{q}(q)$ is a concave function of $q$ and $\left.\left(d \pi^{q}(q) / d q\right)\right|_{q=q^{q^{*}}}=0$. Because of $q^{q^{*}}<q^{*}$, 
$\pi^{q}\left(q^{*}\right)<\pi^{q}\left(q^{q^{*}}\right)$ that is, $\pi\left(q^{*}, p^{*}, \eta^{*}\right)<\pi^{q}\left(q^{q *}, \eta^{q^{*}}\right)$. This completes the proof.

Proposition 7 shows that QC strategy can improve the manufacturer's maximum expected profit when green technology investment and cap and trade policy are taken into account.

\section{Decentralized Supply Chain Model}

In this section, the retailer and the manufacturer make decisions independently to maximize their own expected profit. The manufacturer is the Stackelberg leader and determines the wholesale price and the green technology investment under cap and trade policy. The retailer is the follower and determines the retail price and the order quantity of the product.

The sequence of events in this section is as follows: first, the manufacturer determines the optimal wholesale price, carbon trading, and green technology investment strategies; second, the retailer forms the belief of customers' reservation price and then decides the optimal retail price and order quantity; third, the manufacture produces products and delivers to the retailer; fourth, the customers form the beliefs $\xi_{\text {prob }}$ of probability of the product sold at salvage price $s$ according to the information of market price and then form the reservation price $r$; fifth, the customers' demand is satisfied and the products are sold at full price $p$; finally, all remaining products are sold to the external market at salvage price $s$.

5.1. The Optimal Strategies. First, we examine the decision problem of the retailer. Recall that $w$ is the manufacturer's wholesale price. The retailer's expected profit, denoted by $\pi^{r}(q, p)$, is

$$
\pi^{r}(q, p)=(p-s)\left(q-\int_{0}^{q} F(x) d x\right)-(w-s) q .
$$

Lemma 8. When $p$ is given, $\pi^{r}(q, p)$ is a concave function of $q$.

Proof. When $p$ is given, according to (20), we have $\partial \pi^{r}(q, p) / \partial q=(p-s) \bar{F}(q)-(w-s)$ and $\partial^{2} \pi^{r}(q, p) / \partial q^{2}=$ $-(p-s) f(q)<0$. Then, we know that $\pi^{r}(q, p)$ is a concave function of $q$ when $p$ is given. This completes the proof.

As to the retailer's optimal strategies in RE Equilibrium, we can obtain the following proposition.

Proposition 9. When the wholesale price is given, the retailer's optimal order strategies $\left(q^{r *}\right)$ and optimal pricing strategies $\left(p^{r *}\right)$ with strategic customer behavior are

$$
\begin{aligned}
& q^{r *}=\bar{F}^{-1}\left(\sqrt{\frac{w-s}{v-s}}\right), \\
& p^{r *}=s+\sqrt{(w-s)(v-s) .}
\end{aligned}
$$

Proof. In RE Equilibrium, (9) still holds. Let $\partial \pi^{r}(q, p) / \partial q=0$ and, combining with (9), we have

$$
\begin{aligned}
p & =v-(v-s) F(q), \\
(p-s) \bar{F}(q)-(w-s) & =0 .
\end{aligned}
$$

According to Lemma 8, we can obtain the optimal order and pricing strategies of the retailer by solving the equations above. This completes the proof.

Proposition 9 shows that the retailer's optimal order and pricing strategies in RE Equilibrium with cap and trade policy exist and are unique.

Second, we investigate the manufacturer's decision problem. The expected profit function of the manufacturer with green technology investment and cap and trade policy is $\pi^{m}(w, e, \eta)=(w-c) q-k e-(1 / 2) t \eta^{2}$.

According to (21), with green technology investment and cap and trade policy in wholesale price contract, the optimal order quantity of the retailer $q^{r *}$ and the optimal wholesale price of the manufacturer $w^{m *}$ is a one-to-one relationship:

$$
w=s+(v-s) \bar{F}^{2}(q) .
$$

Combined with $e=(1-\eta) q-E$, the manufacturer's expected profit function can be converted into

$$
\begin{aligned}
\pi^{m}(q, \eta)= & {\left[(v-s) \bar{F}^{2}(q)-(c-s+(1-\eta) k)\right] q } \\
& +k E-\frac{1}{2} t \eta^{2} .
\end{aligned}
$$

When using wholesale price contract, the total profit of the supply chain, denoted by $\pi^{\mathrm{sc}}(q, p, e, \eta)$, is

$$
\begin{aligned}
\pi^{s c}(q, p, e, \eta)= & (p-s)\left(q-\int_{0}^{q} F(x) d x\right)-(c-s) q \\
& -k e-\frac{1}{2} t \eta^{2} .
\end{aligned}
$$

According to (9) and $e=(1-\eta) q-E$, the total supply chain profit function in RE Equilibrium can be simplified as

$$
\begin{aligned}
\pi^{\mathrm{sc}}(q, \eta)= & (v-s) \bar{F}(q)\left(q-\int_{0}^{q} F(x) d x\right) \\
& -(c-s+(1-\eta) k) q+k E-\frac{1}{2} t \eta^{2} .
\end{aligned}
$$

Lemma 10. Given q, the optimal green technology investment strategy of the manufacturer, denoted by $\eta^{m *}$, satisfies

$$
\eta^{m *} \equiv \eta(q)=\frac{k q}{t} \quad 0<\eta^{m *}<1 .
$$

Proof. The first-order and second-order partial derivatives of $\pi^{m}(q, \eta)$ with respect to $\eta$ are $\partial \pi^{m}(q, \eta) / \partial \eta=q k-t \eta$ and $\partial^{2} \pi^{m}(q, \eta) / \partial \eta^{2}=-t<0$. Let $\partial \pi^{m}(q, \eta) / \partial \eta=0$; we get $\eta^{m *} \equiv \eta(q)=k q / t$. In addition, according to the assumption in Section 3, we know $0<\eta^{m *}<1$. This completes the proof. 
Substituting $\eta^{m *}=\eta(q)$ into (25),

$$
\begin{aligned}
\pi^{m}(q) \equiv & \pi^{m}(q, \eta(q)) \\
= & {\left[(v-s) \bar{F}^{2}(q)-(c-s+k)\right] q+k E } \\
& +\frac{k^{2} q^{2}}{2 t} .
\end{aligned}
$$

Then the two-variable optimization problem is simplified as a single variable optimization problem:

$$
\max _{q \geq 0} \pi^{m}(q)
$$

Lemma 11. If $k^{2} / t-2(v-s)\left[2 f(q) \bar{F}(q)+q f^{\prime}(q) \bar{F}(q)-\right.$ $\left.q f^{2}(q)\right]<0, \pi^{m}(q)$ is a concave function of $q$.

Proof. The first-order and second-order derivatives of $\pi^{m}(q)$ with respect to $q$ are $d \pi^{m}(q) / d q=(v-s)\left[\bar{F}^{2}(q)-\right.$ $2 q f(q) \bar{F}(q)]-(c-s+k)+\left(k^{2} / t\right) q$ and $d^{2} \pi^{m}(q) / d q^{2}=$ $k^{2} / t-2(v-s)\left[2 f(q) \bar{F}(q)+q f^{\prime}(q) \bar{F}(q)-q f^{2}(q)\right]<0$. Then we have that $\pi^{m}(q)$ is a concave function of $q$. This completes the proof.

In decentralized supply chain, as to the manufacturer's optimal wholesale price (denoted by $w^{m *}$ ), the following proposition is obtained.

Proposition 12. If $k^{2} / t-2(v-s)\left[2 f(q) \bar{F}(q)+q f^{\prime}(q) \bar{F}(q)-\right.$ $\left.q f^{2}(q)\right]<0$, the manufacturer's optimal wholesale price in decentralized supply chain $\left(w^{m *}\right)$ satisfies $w^{m *}=s+(v-$ s) $\bar{F}^{2}\left(q^{r *}\right)$, where $q^{r *}$ represents the retailer's optimal order quantity and satisfies

$$
\begin{aligned}
& (v-s)\left[\bar{F}^{2}(q)-2 q f(q) \bar{F}(q)\right]-(c-s+k)+\frac{k^{2}}{t} q \\
& \quad=0 .
\end{aligned}
$$

Proof. According to Lemma 11, we can obtain that $q^{r *}$, which maximizes the manufacturer's expected profit, satisfies (31). Combining with (24), we know that the manufacturer's optimal wholesale price satisfies $w^{m *}=s+(v-s) \bar{F}^{2}\left(q^{r *}\right)$ at this time. This completes the proof.

Proposition 12 shows that the optimal commitment quantity of the manufacturer in decentralized supply chain with green technology investment and cap and trade policy exist and are unique. The optimal wholesale price does not relate to the cap allocated by the government but relates to the carbon trading price. This is because the production of the manufacturer is not affected by the cap but is affected by the margin cost of the product. However, the margin cost of the product varies with the change of carbon trading price when carbon trading is allowed. The change results in that the optimal commitment quantity is not related to the cap but relate to the carbon trading price.

Substitute $w^{m *}$ into (22); we derive the retailer's optimal pricing in decentralized situation $p^{r *}=s+\sqrt{\left(w^{m *}-s\right)(v-s)}$.
According to Lemma 10, we get the optimal green technology investment of the manufacturer $\eta^{m *}=(k / t) q^{r *}$.

Substitute $q^{r *}, p^{r *}, w^{m *}$, and $\eta^{m *}$ into $\pi^{r}(q, p), \pi^{m}(q)$, and $\pi^{\mathrm{sc}}(q, \eta)$; we obtain the maximum expected profit of the retailer, the manufacturer, and the supply chain in decentralized channel:

$$
\begin{aligned}
\pi^{r}\left(q^{r *}, p^{r *}\right)= & \left(p^{r *}-s\right)\left(q^{r *}-\int_{0}^{q^{r *}} F(x) d x\right) \\
& -\left(w^{m *}-s\right) q^{r *}, \\
\pi^{m}\left(q^{r *}\right)= & {\left[(v-s) \bar{F}^{2}\left(q^{r *}\right)-(c-s+k)\right] q^{r *} } \\
& +k E+\frac{k^{2} q^{r * 2}}{2 t}, \\
\pi^{\mathrm{sc}}\left(q^{r *}, \eta^{m *}\right)= & (v-s) \bar{F}\left(q^{r *}\right)\left(q^{r *}-\int_{0}^{q^{r *}} F(x) d x\right) \\
& -\left(c-s+\left(1-\eta^{m *}\right) k\right) q^{r *}+k E \\
& -\frac{1}{2} t \eta^{m * 2} .
\end{aligned}
$$

5.2. The Effect of Decentralization. We examine the impact of decentralization on the supply chain optimal strategies and maximum expected profit when green technology investment is taken into consideration by comparing the optimal strategies and the maximum expected profit in centralized and decentralized channel with green technology investment and cap and trade policy.

As the effect of decentralization of supply chain, we can obtain the following proposition.

Proposition 13. Consider $q^{r *}<q^{q *}<q^{*}, p^{r *}>p^{q^{*}}>p^{*}$, $\eta^{m *}<\eta^{q *}<\eta^{*}$

Proof. In Proposition 6, $q^{q^{*}}<q^{*}, p^{q^{*}}>p^{*}$, and $\eta^{q^{*}}<\eta^{*}$ have been proved. Therefore, we only need to prove $q^{r *}<q^{q *}$, $p^{r *}>p^{q *}$, and $\eta^{m *}<\eta^{q *}$.

Define $H(q)=\pi^{q}(q)-\pi^{m}(q)$; then

$H(q)$

$$
\begin{aligned}
= & (v-s) \bar{F}(q)\left(q-\int_{0}^{q} F(x) d x\right) \\
& -(v-s) q \bar{F}^{2}(q),
\end{aligned}
$$

$H^{\prime}(q)$

$$
=(v-s) f(q)\left[2 q \bar{F}(q)-\left(q-\int_{0}^{q} F(x) d x\right)\right] .
$$

Define $G(q)=2 q \bar{F}(q)-\left(q-\int_{0}^{q} F(x) d x\right)$; then $G^{\prime}(q)=$ $\bar{F}(q)-2 q f(q)$. Because $G(0)=0, G^{\prime}(0)=1$, and $F$ satisfies IFR, we know that the value of $G(q)$ starts from 0 , increasing first and then decreasing in $q$. That is, $G(q)=0$ has unique solution and we denote it as $\tilde{q}$. So when $q<\tilde{q}, G(q)>0$; that 
is, $H(q)$ is increasing in $q$; when $q>\widetilde{q}, G(q)<0$; that is, $H(q)$ is decreasing in $q$. Then we have that $H(q)$ is a quasi-concave function of $q$ and $G^{\prime}(\widetilde{q})=\bar{F}(\widetilde{q})-2 \widetilde{q} f(\widetilde{q})<0$. According to the analysis above, we know that $H^{\prime}(\widetilde{q})=0$; that is, $2 \widetilde{q} \bar{F}(\widetilde{q})=$ $\left(\widetilde{q}-\int_{0}^{\widetilde{q}} F(x) d x\right)$. Substitute $\widetilde{q}$ into $d \pi^{q}(q) / d q$; we have

$$
\begin{aligned}
& \left.\frac{d \pi^{q}(q)}{d q}\right|_{q=\tilde{q}} \\
& =(v-s)\left[\bar{F}^{2}(\widetilde{q})-f(\widetilde{q})\left(\tilde{q}-\int_{0}^{\tilde{q}} F(x) d x\right)\right] \\
& \quad-(c-s+k)+\frac{k^{2} \widetilde{q}}{t} \\
& =(v-s) \bar{F}(\tilde{q})[\bar{F}(\tilde{q})-2 \widetilde{q} f(\widetilde{q})]-(c-s+k) \\
& \quad+\frac{k^{2} \widetilde{q}}{t}<(v-s) \bar{F}(\widetilde{q})[\bar{F}(\widetilde{q})-2 \widetilde{q} f(\widetilde{q})]<0 .
\end{aligned}
$$

According to Lemma 4, we have that $\pi^{q}(q)$ is a concave function of $q$, so we get $q^{q *}<\tilde{q}$. Because $2 \widetilde{q} \bar{F}(\widetilde{q})=(\widetilde{q}-$ $\left.\int_{0}^{\widetilde{q}} F(x) d x\right)$ and $H(q)$ is a quasi-concave function of $q$, then we get that $d \pi^{m}(q) / d q<d \pi^{q}(q) / d q$ if $q<\tilde{q}$ and $d \pi^{m}(q) / d q>$ $d \pi^{q}(q) / d q$ if $q>\widetilde{q}$. Therefore, the only possible orderings for $q^{q *}, q^{r *}$, and $\tilde{q}$ are $\tilde{q}<q^{q^{*}}<q^{r *}$ and $q^{r *}<q^{q *}<\widetilde{q}$. We have proved $q^{q *}<\tilde{q}$, so we have $q^{r *}<q^{q^{*}}$. We get $p^{r *}>p^{q^{*}}$ because $p$ and $q$ satisfy $p=v-(v-s) F(q)$ in two situations. We get $\eta^{m *}<\eta^{q *}$ because $\eta$ and $q$ satisfy $\eta=k q / t$ in two situations. This completes the proof.

Proposition 13 shows that for the decision of a decentralized supply chain with green technology investment, the optimal production quantity is increasing, the optimal price is decreasing, and the green technology investment (i.e., carbon reduction rate) is increasing, respectively, in the three situations of decentralized supply chain, QC scenario, and RE Equilibrium scenario.

The reason is that the manufacturer prefers higher wholesale price (i.e., lower production and less green technology investment) to guarantee its own profit maximization, though this may harm the retailer, even the whole supply chain.

In Proposition 7 , we have found $\pi^{q}\left(q^{q^{*}}, \eta^{q^{*}}\right)>$ $\pi\left(q^{*}, p^{*}, \eta^{*}\right)$; that is, the manufacturer's maximum profit in QC scenario is always greater than that in RE Equilibrium. Therefore, the section analyzes the effect of decentralization on supply chain performance based on the QC scenario to provide benchmark for designing of subsequent coordination contract.

As to the effect of decentralization on the maximum profit of supply chain, we have the following proposition.

Proposition 14. Consider $\pi^{\mathrm{sc}}\left(q^{r *}, \eta^{m *}\right)<\pi^{q}\left(q^{q *}, \eta^{q *}\right)$.

Proof. The optimal green technology investment in decentralized supply chain and QC scenario are $\eta(q)=\mathrm{kq} / \mathrm{t}$ according to Lemmas 3 and 10 . So the profit function in the two situations above can be converted into a same single variable function with respect to $q$, that is, (16).
According to Lemma 4, we know that $\pi^{q}(q)$ is a concave function and reaches the maximum value at $q^{q *}$. According to Proposition 13, we have $q^{r *}<q^{q *}$; then we get $\pi^{q}\left(q^{r *}\right)<$ $\pi^{q}\left(q^{q *}\right)$; that is, $\pi^{\mathrm{sc}}\left(q^{r *}, \eta^{m *}\right)<\pi^{q}\left(q^{q *}, \eta^{q^{*}}\right)$. This completes the proof.

Proposition 14 shows that the maximum profit of decentralized supply chain is always lower than that in QC scenario which indicates that the profit of the decentralized supply chain can get higher. This is the benchmark of supply chain coordination.

\section{Supply Chain Coordination}

This section coordinates the supply chain with green technology investment and cap and trade policy based on the QC scenario to improve the profit of the decentralized supply chain.

6.1. Coordination Contract Based on Revenue and Costs Sharing Contract. With revenue sharing contract, we assume that $\phi(0 \leq \phi \leq 1)$ represents the ratio of revenue kept by the retailer and $(1-\phi)$ represents the ratio of revenue delivered to the manufacturer.

The retailer's expected profit function with revenue sharing contract, denoted by $\pi_{s}^{r}(q, p, \phi)$, is

$$
\begin{aligned}
\pi_{s}^{r}(q, p, \phi)= & \phi(p-s)\left(q-\int_{0}^{q} F(x) d x\right) \\
& -(w-\phi s) q .
\end{aligned}
$$

The manufacturer's expected profit function with revenue sharing contract, denoted by $\pi_{s}^{m}(w, e, \eta, \phi)$, is

$$
\begin{gathered}
\pi_{s}^{m}(w, e, \eta, \phi)=(w-c) q+(1-\phi) \\
\cdot\left[\int_{0}^{q}[p x+s(q-x)] f(x) d x\right. \\
\left.+\int_{q}^{\infty} p q f(x) d x\right]-k e-\frac{1}{2} t \eta^{2} .
\end{gathered}
$$

Substitute $e=(1-\eta) q-E$ into the equation above and we have

$$
\begin{aligned}
\pi_{s}^{m}(w, \eta, \phi)= & (1-\phi)(p-s)\left(q-\int_{0}^{q} F(x) d x\right) \\
& +(w-c-(1-\eta) k+(1-\phi) s) q \\
& +k E-\frac{1}{2} t \eta^{2} .
\end{aligned}
$$

The total expected profit of the whole supply chain, denoted by $\pi_{s}^{\mathrm{sc}}(q, p, \eta)$, is

$$
\begin{aligned}
\pi_{s}^{\mathrm{sc}}(q, p, \eta)= & (p-s)\left(q-\int_{0}^{q} F(x) d x\right) \\
& -(c-s+(1-\eta) k) q+k E-\frac{1}{2} t \eta^{2} .
\end{aligned}
$$


The subscript $s$ represents the situation of supply chain coordination using revenue sharing contracts.

As to the retailer's optimal order strategy (denoted by $q_{s}^{*}$ ) and pricing strategy (denoted by $p_{s}^{*}$ ) of the supply chain with revenue sharing contract, the following proposition is obtained.

Proposition 15. Under revenue sharing contracts, the retailer's optimal order strategy $\left(q_{s}^{*}\right)$ and optimal pricing strategy $\left(p_{s}^{*}\right)$ are

$$
\begin{aligned}
& q_{s}^{*}=\bar{F}^{-1}\left(\sqrt{\frac{w-\phi s}{\phi(v-s)}}\right), \\
& p_{s}^{*}=s+\sqrt{\frac{(w-\phi s)((v-s))}{\phi}} .
\end{aligned}
$$

Proof. According to the definition of RE Equilibrium, we also have $p=v-(v-s) F(q)$ under revenue sharing contracts.

The first-order and second-order derivative of $\pi_{s}^{r}(q, p, \phi)$ with respect to $q$ are $\partial \pi_{s}^{r}(q, p, \phi) / \partial q=\phi(p-s) \bar{F}(q)-$ $(w-\phi s)$ and $\partial^{2} \pi_{s}^{r}(q, p, \phi) / \partial q^{2}=-\phi(p-s) f(q)<$ 0 . So given $p$, the retailer's expected profit function is a concave function of $q$. Let $\partial \pi_{s}^{r}(q, p, \phi) / \partial q=0$ and combine with $p=v-(v-s) F(q)$, we can solve the retailer's optimal strategies under revenue sharing contract. This completes the proof.

Proposition 15 shows that the optimal order and pricing strategies of the retailer based on revenue sharing contract in $\mathrm{RE}$ Equilibrium exist and are unique. This is also the retailer's optimal response function with respect to $w$.

Substituting (39) into (43),

$$
\begin{aligned}
& \pi_{s}^{m}(q, \eta, \phi) \\
& =(1-\phi)(v-s) \bar{F}(q)\left(q-\int_{0}^{q} F(x) d x\right) \\
& \quad+\left[\phi(v-s) \bar{F}^{2}(q)-(c-s+(1-\eta) k)\right] q+k E \\
& \quad-\frac{1}{2} t \eta^{2}, \\
& \frac{\partial \pi_{s}^{m}(q, \eta, \phi)}{\partial \eta}=q k-t \eta, \\
& \frac{\partial^{2} \pi_{s}^{m}(q, \eta, \phi)}{\partial \eta^{2}}=-t<0 .
\end{aligned}
$$

Given $q$ and $\phi$, the manufacturer's green technology investment strategies with revenue sharing contracts exist and are unique. Let $\partial \pi_{s}^{m}(q, \eta, \phi) / \partial \eta=0$; we get $\eta_{s}^{m *} \equiv \eta(q)=$ $q k / t$, and substitute it into $\pi_{s}^{m}(q, \eta, \phi)$ :

$$
\begin{aligned}
\pi_{s}^{m}(q, \phi) & \\
= & (v-s) \bar{F}(q)\left(q-\int_{0}^{q} F(x) d x\right) \\
& +\phi(v-s) \bar{F}(q)\left[q \bar{F}(q)-\left(q-\int_{0}^{q} F(x) d x\right)\right] \\
& -(c-s+k) q+k E+\frac{k^{2} q^{2}}{2 t} .
\end{aligned}
$$

Proposition 16. The supply chain with green technology investment and cap and trade policy can not be coordinated by revenue sharing contract.

Proof. The derivative of $\pi_{s}^{m}(q, \phi)$ with respect to $q$ can be arranged as follows:

$$
\frac{\partial \pi_{s}^{m}(q, \phi)}{\partial q}=\frac{\partial \pi^{q}(q)}{\partial q}+\phi\left(\frac{\partial \pi^{m}(q)}{\partial q}-\frac{\partial \pi^{q}(q)}{\partial q}\right) .
$$

Only when $\phi=0$ are the optimal strategies of supply chain under revenue sharing contracts equal to that in QC scenario. Let $w_{s}^{*}$ represent the optimal wholesale price of the manufacture and $q_{s}^{*}$ represent the retailer's optimal order quantity. Then $\pi_{s}^{r}(q, p, \phi)=-w_{s}^{*} q_{s}^{*}<0$. So the revenue sharing contract can not realize the supply chain coordination at this time. This completes the proof.

Proposition 16 shows that revenue sharing contracts can not realize the supply chain coordination with green technology investment and cap and trade policy. The reason is that the manufacturer undertakes all the costs of green technology investment when using revenue sharing contracts, thus making the manufacturer tend to invest less in green technology. Only when the manufacturer owns all the revenue will the manufacturer's optimal green technology investment under revenue sharing contracts be equal to that in QC scenario. However, the maximum profit of the retailer is negative at this time and it will not participate.

6.2. Coordination Contract Based on Revenue Sharing-Cost Sharing Contract. Proposition 16 states that the supply chain with green technology investment and cap and trade policy can not be coordinated by revenue sharing contracts because the costs of green technology investment are undertaken by the manufacturer and the game of retailer and customers is characterized by RE Equilibrium. So we consider costs sharing of green technology investment and carbon trading and quantity commitment made by the manufacturer based on revenue sharing contracts. Let $\phi(0<\phi \leq 1)$ represent the ratio of revenue kept by the retailer and let $(1-\phi)$ represent the ratio of revenue delivered to the manufacturer. $\alpha(0 \leq \alpha \leq 1)$ represents the ratio of costs of green technology investment and carbon trading undertaken by the manufacturer and $(1-\alpha)$ represents the ratio of costs of green technology investment and carbon trading delivered to the retailer. 
The retailer's expected profit function with revenue sharing-cost sharing contract is

$$
\begin{aligned}
\pi_{\alpha}^{r}(q, \phi, \alpha)= & \phi(v-s) \bar{F}(q)\left(q-\int_{0}^{q} F(x) d x\right) \\
& -(w-\phi s) q \\
& -(1-\alpha) k[(1-\eta) q-E] \\
& -\frac{1}{2}(1-\alpha) t \eta^{2} .
\end{aligned}
$$

We have $e=(1-\eta) q-E$; then the manufacturer's expected profit function, denoted by $\pi_{\alpha}^{m}(w, \eta, \phi, \alpha)$, is

$$
\begin{aligned}
& \pi_{\alpha}^{m}(w, \eta, \phi, \alpha) \\
&=(1-\phi)(v-s) \bar{F}(q)\left(q-\int_{0}^{q} F(x) d x\right) \\
&+(w-c-\alpha(1-\eta) k+(1-\phi) s) q+\alpha k E \\
&-\frac{1}{2} \alpha t \eta^{2} .
\end{aligned}
$$

The subscript $\alpha$ represents the situation that using revenue sharing-cost sharing contract coordinates the supply chain.

Proposition 17. If $0 \leq \lambda \leq 1$, the parameters of revenue sharing-cost sharing $(w, \phi, \alpha)$ satisfy

$$
\begin{aligned}
& w=\lambda c+(1-\eta) k, \\
& \phi=\lambda, \\
& \alpha=1-\lambda .
\end{aligned}
$$

The supply chain with green technology investment and cap and trade policy is coordinated.

Proof. When the parameters of revenue sharing-cost sharing satisfy (45), the expected profit function of the retailer and the manufacturer can be written as follows:

$$
\begin{aligned}
\pi_{\alpha}^{r}(q, p, \phi, \alpha) & =\lambda \pi^{q}(q, \eta), \\
\pi_{\alpha}^{m}(w, \eta, \phi, \alpha) & =(1-\lambda) \pi^{q}(q, \eta) .
\end{aligned}
$$

The optimal order of decentralized supply chain is equal to that of QC scenario. Substitute $p=v-(v-s) F(q)$ into $\pi_{c}^{\mathrm{sc}}(q, p, \eta)$; we get that the profit function of decentralized supply chain at this time is the same as that of QC scenario. Therefore, when the parameters of revenue sharing-cost sharing $(w, \phi, \alpha)$ satisfy (45), the decentralized supply chain coordination is realized. The manufacturer earns all the profit if $\lambda=0$ and the retailer earns all the profit if $\lambda=1$. Arbitrary allocation of the supply chain profit between the manufacturer and the retailer is allowed. This completes the proof.

Proposition 17 shows that revenue sharing-cost sharing contract can realize the supply chain coordination on condition that the manufacturer makes a quantity commitment to the customers. The optimal production quantity and green technology investment in decentralized situation are lower than that in QC scenario. The quantity commitment of the manufacturer can increase the green technology investment and production quantity and also reduce the retailer price. That is, the quantity commitment is beneficial for the manufacturer, the retailer, and customers. Thus, the quantity commitment is credible to customers now.

\section{Conclusions and Suggestions for Further Research}

This paper investigates the production, pricing, carbon trading, and green technology investment strategies and the coordination of low carbon supply chain made up of a low carbon manufacturer and a retailer. The low carbon manufacturer produces one product under cap and trade policy and performs green technology investment to reduce carbon emissions in production process. The retailer orders from the manufacturer and distributes the product to homogenous customers. To the best of our knowledge, this is the first study on the management of low carbon supply chains with strategic customer behavior. This paper provides several interesting observations.

Observation 1. There are unique optimal production, pricing, carbon trading, and green technology investment strategies in centralized (include RE Equilibrium scenario and QC scenario) and decentralized supply chain. Therefore, by deriving the optimal production, pricing, carbon trading, and green technology investment strategies in different situations, the low carbon manufacturer and the retailer can behave appropriately based on our findings to maximize their profit.

Observation 2. Our findings also show that the centralized supply chain can improve its performance by quantity commitment. However, the manufacturer's production and green technology investment are reduced while the optimal price is increased at this time. Therefore, quantity commitment is beneficial for the supply chain but is harmful to customers.

Observation 3. We also show that the performance of decentralized supply chain is lower than that in QC scenario. We find that the decentralization reduces the manufacture's optimal production quantity and green technology investment and increases the retailer's optimal price. Besides, we find that the optimal production quantity is increasing, the optimal price is decreasing, and the green technology investment is increasing, respectively, in the three situations of decentralized supply chain, QC scenario, and RE Equilibrium scenario.

Observation 4. We demonstrate that the traditional revenue sharing contracts can not realize the low carbon supply chain coordination when green technology investment is taken in consideration. We also find that the revenue sharingcost sharing contract realizes the decentralized supply chain 
coordination when the manufacturer makes a quantity commitment. It is beneficial to the manufacturer, the retailer, and customers if the manufacturer makes a quantity commitment. So the quantity commitment is credible to the customer at this time.

We assume the customers are homogeneous strategic customers. But the myopic customers and strategic customers often coexist and strategic customers also have different tolerance in real-life. Extending this assumption will have a knock-on effect on supply chain decisions. So one key research direction is to consider that the customers are mixed customers: myopic customers and strategic customers. Second, we assume that the supply chain only produces one product. While this simplified setting provides some interesting insights, we have to acknowledge that a manufacturer usually produces two or more products. These products will substitute or complement each other. So one important extension of our work is to assume that the manufacturer produces two or more products, which have different unit carbon emissions in production.

\section{Notations}

$D: \quad$ The random demand and $D \geq 0$

$f(\cdot)$ : Probability density function of $D$

$F(\cdot)$ : Distribution function of $D$. We assume that $F$ satisfy IFR and define $\bar{F}=1-F$

$c$ : Unit production cost

$s$ : Unit salvage price of the product which is an exogenous variable

$v$ : The customers' utility from consuming the product

$w$ : Unit wholesale price

$p$ : Unit retail selling price. We assume that it can be observed by the customers

$q$ : The manufacturer's production quantity/the retailer's order quantity. We assume that it cannot be observed by the customers

$r$ : The customers' reservation price, which is customers' private information and cannot be observed by the retailer

$\xi_{r}$ : The beliefs of the manufacturer over the customer' reservation price

$\xi_{\text {prob}}$ : The beliefs of customers over their chances of obtaining the product at phase two

E: Initial free carbon emission allocated by government

$k$ : Unit carbon emission trading price

$e$ : Carbon trading volume

$\eta$ : $\quad$ Carbon emissions reduction rate.

\section{Conflict of Interests}

The authors declare no conflict of interests.

\section{Acknowledgments}

This research is partially supported by National Natural Science Foundation of China (nos. 71432003 and 71272128), the Program for New Century Excellent Talents in University (no. NCET-12-0087), and Specialized Research Fund for the Doctoral Program of Higher Education (no. 20130185110006).

\section{References}

[1] R. Alley, T. Berntsen, N. L. Bindoff et al., "Summary for policymakers," in Climate Change 2007: The Physical Science Basis, vol. 6, pp. 1-18, IPCC, 2007.

[2] X. Chen and G. Hao, "Sustainable pricing and production policies for two competing firms with carbon emissions tax," International Journal of Production Research, vol. 53, pp. 64086420, 2015.

[3] X. Chen, S. Benjaafar, and A. Elomri, "The carbon-constrained EOQ," Operations Research Letters, vol. 41, no. 2, pp. 172-179, 2013.

[4] N. O. Keohane, "Cap and trade, rehabilitated: using tradable permits to control U.S. greenhouse gases," Review of Environmental Economics and Policy, vol. 3, no. 1, pp. 42-62, 2009.

[5] B. Liu, M. Holmbom, A. Segerstedt, and W. Chen, "Effects of carbon emission regulations on remanufacturing decisions with limited information of demand distribution," International Journal of Production Research, vol. 53, no. 2, pp. 532-548, 2015.

[6] L. Zhu and Y. Fan, "A real options-based CCS investment evaluation model: case study of China's power generation sector," Applied Energy, vol. 88, no. 12, pp. 4320-4333, 2011.

[7] X. Wang and L. Du, "Study on carbon capture and storage (CCS) investment decision-making based on real options for China's coal-fired power plants," Journal of Cleaner Production, vol. 112, part 5, pp. 4123-4131, 2016.

[8] W. Jiang and X. Chen, "Optimal strategies for manufacturer with strategic customer behavior under carbon emissionssensitive randomdemand," Industrial Management \& Data Systems, 2015.

[9] Y. Levin, J. McGill, and M. Nediak, "Dynamic pricing in the presence of strategic consumers and oligopolistic competition," Management Science, vol. 55, no. 1, pp. 32-46, 2009.

[10] A. K. Parlaktürk, "The value of product variety when selling to strategic consumers," Manufacturing \& Service Operations Management, vol. 14, no. 3, pp. 371-385, 2012.

[11] X. Su and F. Zhang, "On the value of commitment and availability guarantees when selling to strategic consumers," Management Science, vol. 55, no. 5, pp. 713-726, 2009.

[12] W. Elmaghraby, S. A. Lippman, C. S. Tang, and R. Yin, "Will more purchasing options benefit customers?" Production and Operations Management, vol. 18, no. 4, pp. 381-401, 2009.

[13] W. Jiang and X. Chen, "Manufacture's production and pricing strategies with carbon tax policy and strategic customer behavior," Management Science and Engineering, vol. 9, no. 1, pp. 3035, 2015.

[14] I. Dobos, "The effects of emission trading on production and inventories in the Arrow-Karlin model," International Journal of Production Economics, vol. 93-94, pp. 301-308, 2005.

[15] X. Chen, C. K. Chan, and Y. C. E. Lee, "Responsible production policies with substitution and carbon emissions trading," Journal of Cleaner Production, 2015. 
[16] X. Chen and X. Wang, "Effects of carbon emission reduction policies on transportation mode selections with stochastic demand," Transportation Research Part E: Logistics and Transportation Review, 2015.

[17] X. Chang, H. Xia, H. Zhu, T. Fan, and H. Zhao, "Production decisions in a hybrid manufacturing-remanufacturing system with carbon cap and trade mechanism," International Journal of Production Economics, vol. 162, pp. 160-173, 2015.

[18] J. Zhao, B. F. Hobbs, and J.-S. Pang, "Long-run equilibrium modeling of emissions allowance allocation systems in electric power markets," Operations Research, vol. 58, no. 3, pp. 529-548, 2010.

[19] B. Yalabik and R. J. Fairchild, "Customer, regulatory, and competitive pressure as drivers of environmental innovation," International Journal of Production Economics, vol. 131, no. 2, pp. 519-527, 2011.

[20] A. Toptal, H. Özlü, and D. Konur, "Joint decisions on inventory replenishment and emission reduction investment under different emission regulations," International Journal of Production Research, vol. 52, no. 1, pp. 243-269, 2014.

[21] A. S. Manikas and J. R. Kroes, "A newsvendor approach to compliance and production under cap and trade emissions regulation," International Journal of Production Economics, vol. 159, pp. 274-284, 2015.

[22] S. Benjaafar, Y. Li, and M. Daskin, "Carbon footprint and the management of supply chains: insights from simple models," IEEE Transactions on Automation Science and Engineering, vol. 10, no. 1, pp. 99-116, 2013.

[23] X. Xu, W. Zhang, P. He, and X. Xu, "Production and pricing problems in make-to-order supply chain with cap-and-trade regulation," Omega, 2015.

[24] Y. Zhen, X. Yang, and W. Jiang, "The impact of transport mode and carbon policy on low-carbon retailer," Discrete Dynamics in Nature and Society, vol. 2015, Article ID 964305, 12 pages, 2015.

[25] S. Swami and J. Shah, "Channel coordination in green supply chain management," Journal of the Operational Research Society, vol. 64, no. 3, pp. 336-351, 2013.

[26] R. H. Coase, "Durability and monopoly," The Journal of Law and Economics, vol. 15, no. 1, pp. 143-149, 1972.

[27] X. Su, "Intertemporal pricing with strategic customer behavior," Management Science, vol. 53, no. 5, pp. 726-741, 2007.

[28] D. Zhang and W. L. Cooper, "Managing clearance sales in the presence of strategic customers," Production and Operations Management, vol. 17, no. 4, pp. 416-431, 2008.

[29] S. Whang, "Demand uncertainty and the Bayesian effect in markdown pricing with strategic customers," Manufacturing \& Service Operations Management, vol. 17, no. 1, pp. 66-77, 2015.

[30] J. Du, J. Zhang, and G. Hua, "Pricing and inventory management in the presence of strategic customers with risk preference and decreasing value," International Journal of Production Economics, vol. 164, pp. 160-166, 2015.

[31] X. Su and F. Zhang, "Strategic customer behavior, commitment, and supply chain performance," Management Science, vol. 54, no. 10, pp. 1759-1773, 2008.

[32] H. Yang, "Impact of discounting and competition on benefit of decentralization with strategic customers," Operations Research Letters, vol. 40, no. 2, pp. 123-127, 2012.

[33] D. Yang, E. Qi, and Y. Li, "Quick response and supply chain structure with strategic consumers," Omega, vol. 52, pp. 1-14, 2015.
[34] C. d'Aspremont and A. Jacquemin, "Cooperative and noncooperative R \& D in duopoly with spillovers," The American Economic Review, vol. 78, no. 5, pp. 1133-1137, 1988.

[35] J. F. Muth, "Rational expectations and the theory of price movements," Econometrica, vol. 29, no. 3, pp. 315-335, 1961. 


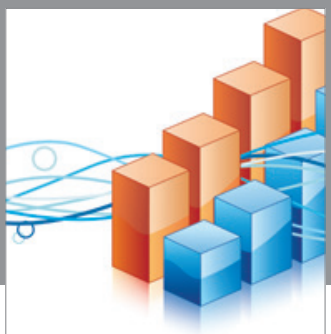

Advances in

Operations Research

vatem alat4

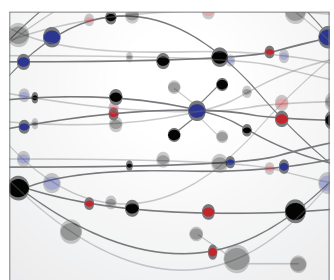

\section{The Scientific} World Journal
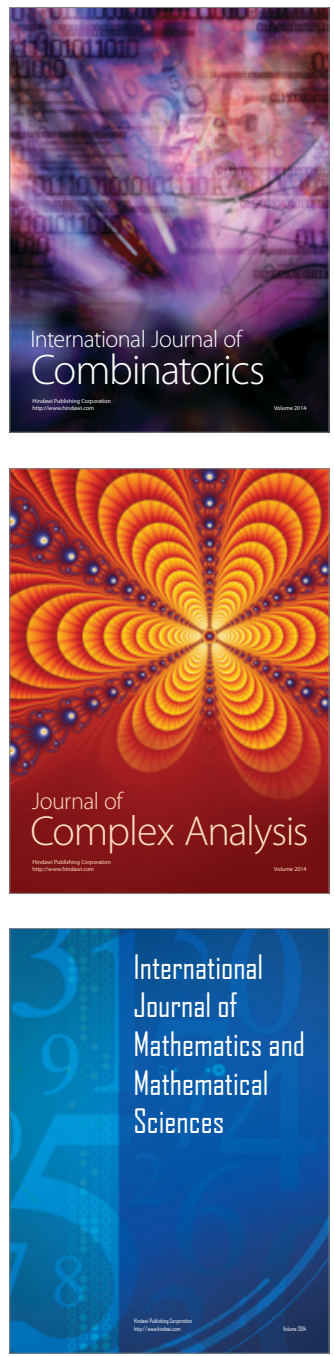
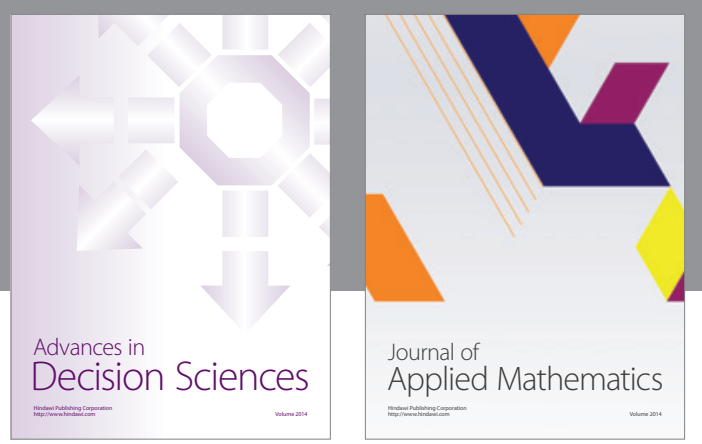

Algebra

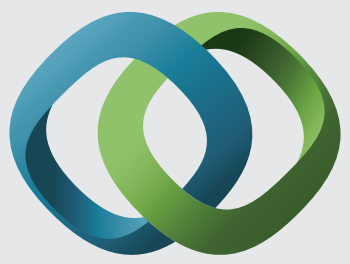

\section{Hindawi}

Submit your manuscripts at

http://www.hindawi.com
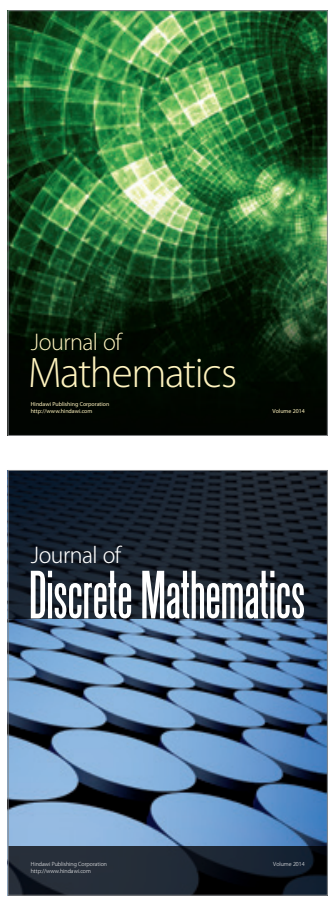

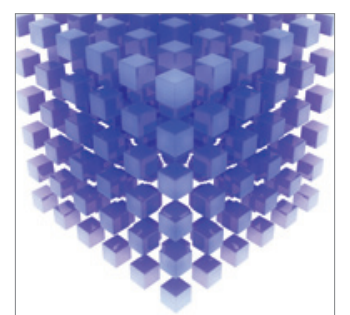

Mathematical Problems in Engineering
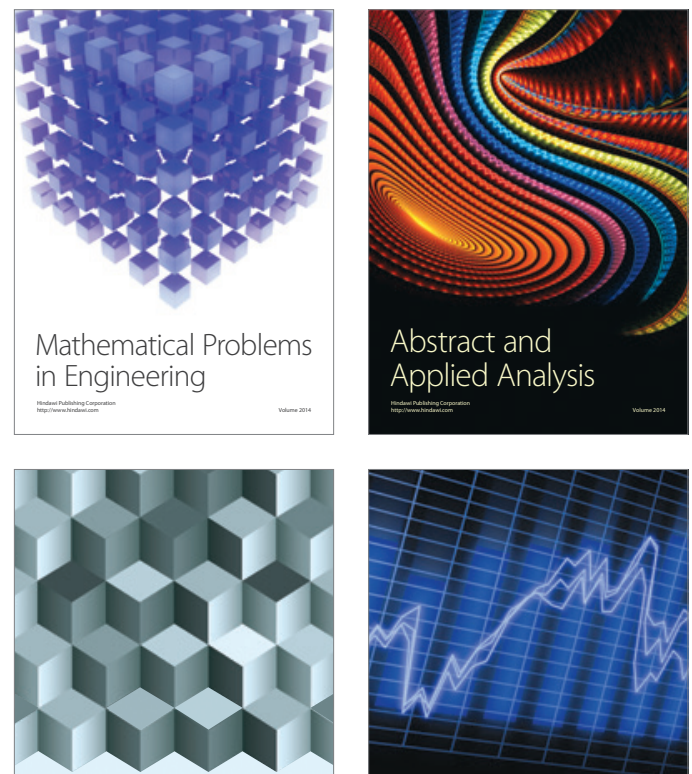

Journal of

Function Spaces

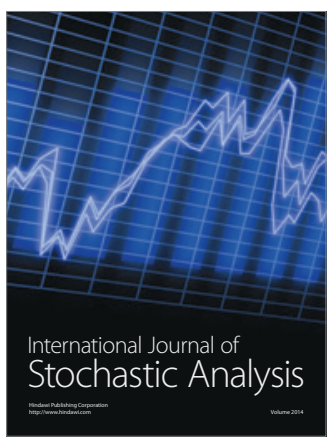

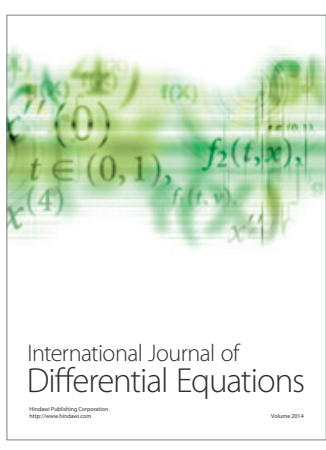
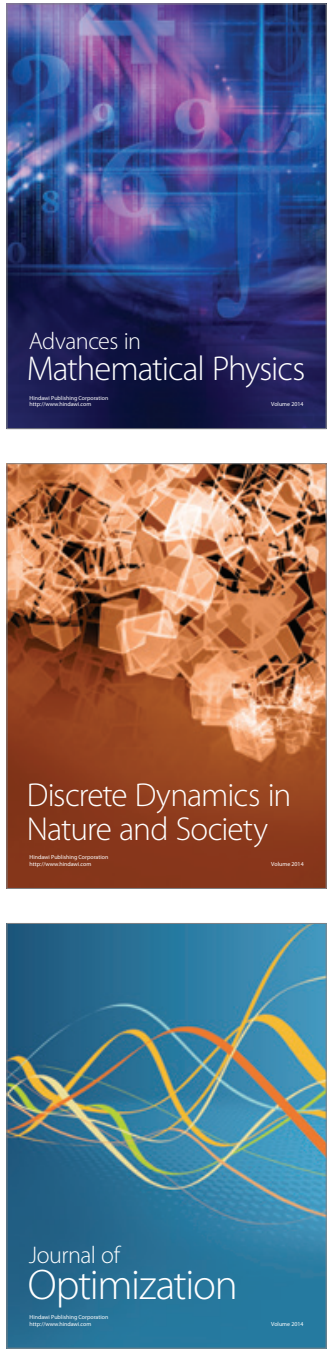